\title{
PREFERRED METHOD OF PURCHASING SUPPLEMENTS AMONG GOVERNMENT SERVANTS IN PUTRAJAYA
}

\author{
Nurul Syakilah Embok Raub ${ }^{1}$ and Hazreen Abdul Majid ${ }^{1,2}$ \\ ${ }^{1}$ Centre for Population Health, Department of Social and Preventive Medicine, Faculty of Medicine, \\ University of Malaya, 50603 Kuala Lumpur, Malaysia. \\ ${ }^{2}$ Department of Nutrition, Faculty of Public Health, Universitas Airlangga, 60115, Jawa Timur, Indonesia
}

Corresponding author: Nurul Syakilah Embok Raub.

Email: nurul_syakilah@yahoo.com.my

\begin{abstract}
Despite the risk of buying dangerous unregistered or counterfeit health supplement products online, the purchases still persist. This study aimed to identify the current preferred purchasing method and factors that influenced the preference. A cross-sectional study using simple random sampling was conducted among supplement purchasers within government servants in Putrajaya, Malaysia. Data were collected using an online self-reported questionnaire from $1^{\text {st }}$ February to $1^{\text {st }}$ August 2020. The traditional method became the preferred way of purchasing supplements (Traditional $=68 \%$ vs Online $=32 \%)$. However, younger and middle group $(O R=2.13,95 \% \mathrm{Cl}=1.41-3.21$ and $O R=2.16$, $95 \% \mathrm{Cl}=1.22-3.82$, respectively), females $(O R=1.38,95 \% \mathrm{Cl}=1.05-1.80)$ and, non-Malays (Indian and others, OR $=$ $0.33,95 \% \mathrm{Cl}=0.11-0.95$ and $O R=0.38,95 \% \mathrm{Cl}=0.17-0.88$, respectively) significantly preferred online purchases. Product quality was the most important factor for both purchasing methods $(P<0.001)$. Meanwhile, the main motivating factor for choosing the traditional method was 'ease of getting the product advise and relevant information' ( $n=595,72.4 \%)$, in online, it was 'being able to read the product reviews through the internet (IT)' $(n=205,52.8 \%)$. The majority of respondents checked for many similar supplement products before purchase $(50.9 \%$ Traditional and $38.4 \%$ Online). Surprisingly, no significant differences were found in knowledge for identifying registered products between both methods $(p=0.330)$. The traditional method was still preferred and indicates that, the health awareness of the respondents is encouraging. However, this result cannot be generalized to the population. Hence, efforts to enhance public knowledge, awareness, and promoting the safety and efficacious issues on registered supplement products must be continued.
\end{abstract}

Keywords: Supplements, traditional, online, unregistered supplements, counterfeit supplements

\section{INTRODUCTION}

Technology advancement and the dumping of products online have greatly changed people buying patterns. In fact, people today prefer to buy products online compared to the traditional method, where they buy directly from the seller. According to an international study, the consumers in Asia, North America, and Western Europe were most likely to shop online ${ }^{1}$. Buying medications and supplements online were no exception, and have become a trend that was expected to continue ${ }^{2}$. Unfortunately, buying supplements online can expose users to the risks of using supplements that are not registered or counterfeited that may cause adverse effects, and even fatality ${ }^{3}$. According to the World Health Organization $(2014)^{4}$, counterfeit drugs and supplements posed a significant danger to public health worldwide. An estimated $10 \%$ of global pharmaceutical commerce, or \$ 21 USD billion worth, involves counterfeit drugs and supplements ${ }^{5}$.

Malaysia, as a developing country, also faced the problem of counterfeit drugs and supplements. A study by Ministry of Health $(\mathrm{MOH})$ Malaysia revealed that $5 \%$ of the medicines in Malaysia were counterfeit ${ }^{6}$. Despite many reports related to the sale of counterfeit supplement products and the side effects ${ }^{3}$, there were still consumers purchase online ${ }^{1,7}$. Sociodemographic characteristics, the influencing factor, motivational factor and knowledge on how to identify registered products in the market are known to affect the method of purchasing supplements. It was found that age, gender, ethnicity, education, and income status affect this purchasing preference ${ }^{7-8}$. The younger generations were more technologically advance and had more user experience than older generations, thus make this group more prominent in online purchase $e^{2,7-9}$. For gender, the female had a greater propensity towards online purchase intention due to more females have technological shopping skills ${ }^{7}$. In terms of ethnicity, a study in Malaysia revealed that internet purchasing was significantly associated with Chinese ethnic groups $^{10}$. Whereas, education is a crucial factor in purchasing online as people were more IT literate as found in three studies $^{2,7-8}$. Meanwhile, higher-income people tend to buy more online, for its reliability and convenience. The better the income, the greater the will to purchase online products ${ }^{8}$. 
Comparative studies of purchasing behaviour revealed that factors that influenced the method were price, quality, time, convenience, and trust to the sellers ${ }^{7-12}$. From another study, motivational factors such as economic, technical, service, and social values could also influence purchasing method ${ }^{11}$. As for the prepurchase behaviour, people would tend to evaluate their future choice based on their level of satisfaction with past purchasing experiences $^{13}$. Meanwhile, another literature that focused on the product purchase phase revealed that most of their participants were inclined to check many similar products before they decided on the product they wanted to buy as their purchase strategy. None of the participants purchased products that had been recommended to them by the seller ${ }^{11}$.

Whereas consumers, who are more alert about problems associated with the effects of counterfeit products, may have more positive attitudes towards purchasing noncounterfeit products $^{14}$, thus may be inclined to engage with purchasing method that is consistent with their knowledge on registered products. A study in Malaysia on the registered products knowledge revealed that about $40.8 \%$ of the patients were in the category of the acceptable level of knowledge $^{15}$. However, to our knowledge, no known study looks specifically into the preference of purchasing methods for supplement products. Hence, this study aimed to identify the current preferred method of purchasing supplement products and to look into factors that influenced their preference.

\section{METHODS}

\section{Setting and Sample}

A cross-sectional survey was conducted among the government servants in Putrajaya, Malaysia. Eligibility for enrolment into the study was considered to those who are purchasers of any supplement products. The data collection was conducted for five months, starting from 1st Feb 2020 until 1st August 2020.

\section{Ethical Consideration}

This research obtained ethical approvals from the University of Malaya Research Ethics Committee (UMREC), National Medical Research Registration (NMRR) (specifically for the ministry of health), and the Educational Research Application System (ERAS) (specifically for the ministry of education).

\section{Questionnaire Development and Distribution}

The data was collected from the online survey which used the structured online-administered questionnaire. The questionnaire was adapted from two studies titled 'Young Consumers Online and Offline Channel Purchase Behavior'11 and 'Development of Validated Questionnaire to Access Public Knowledge on Registered Drugs'16.
Permission to use the questionnaire was obtained from Zulkifli NW et.al $(2015)^{16}$, while the questionnaire from Lalwani $(2017)^{11}$ was extracted from open access. The questionnaire was then designed to match with the elements of this study's objectives, and integrated with Pharmacy Division Information based on the pharmacy department portal, in the section titled 'How to Identify Medicines That Are Registered With MOH?'. The questionnaire was prepared in English which consist of six sections (sociodemographic, preference method, influencing and motivational factors, attitude, and knowledge) and was translated into the Malay language by the researcher. A pre-test was then carried out for one week; from 4th to 8th Nov 2019, consisted of ten people from the target population (government servants from various places) for preliminary confirmation on the designed questionnaire to gauge respondent's understanding. No additional improvement was done as there was no feedback from respondents on difficulties in answering the questionnaire. The questionnaire for this study was given in dual languages -English and Malay. This online survey was conducted through the platform of google form which had been posted via two generated links (https: / / forms.gle/JKRQPLEdmJbbxWRN8) and (https: //forms.gle/SFuiCoc4upGpn82MA). The dissemination of the online form to respondents had been done through each official ministry email and official permission through a request letter to all heads of each government sector had been obtained before the link was posted.

\section{Sample Recruitment}

All the respondents were informed of the objectives of the study, and online consent was obtained before they participated in this study. Respondents were then selected using a simple random sampling method and there were no additional steps, in which regardless of the ministry, those who had agreed and were eligible to participate were processed. Out of 1358 respondents, only 1329 had agreed to participate and were eligible in this survey. The number was further reduced to 1327 respondents as two from the Ministry of Water, Land, and Natural Resources were excluded on their request. Thus, the respondents from each ministry were selected based on the proportion of the total respondents for each ministry against the percentages of the total respondents (1327 respondents), to allow for only 1210 total samples recruited as per the calculated sample size for this study as shown in Figure 1. The selection was based on a random count of every five respondents to get to a total respondent of that particular ministry. This process was then repeated with other ministries to get the total respondents for each ministry, and these total respondents from each ministry will be added to get 1210 recruitment. 


\section{Data Analysis}

All processed data were treated as anonymized data and were entered into a passwordprotected database using the SPSS V21 (IBM, Armonk, New York, USA). The descriptive analyses were produced for all demographic variables and expressed as numbers and percentages. A Chi-Square Test was applied for testing the association between the influencing factors with the preferred method, whereas logistic regression analysis was used to identify the factors associated with online purchasing. The dependent factor was the preferred method, whereas, the independent factors were sociodemographic characteristics. The $\mathrm{t}$-Test analysis was used to compare knowledge on identifying registered supplement products between traditional and online groups. Nine true or false close-ended questions were scored based on one point for each correct answer, and the result was measured on the total correct answers. All analyses were set at an alpha error of 0.05 with a $95 \%$ confidence level for this study's findings to become statistically significant.

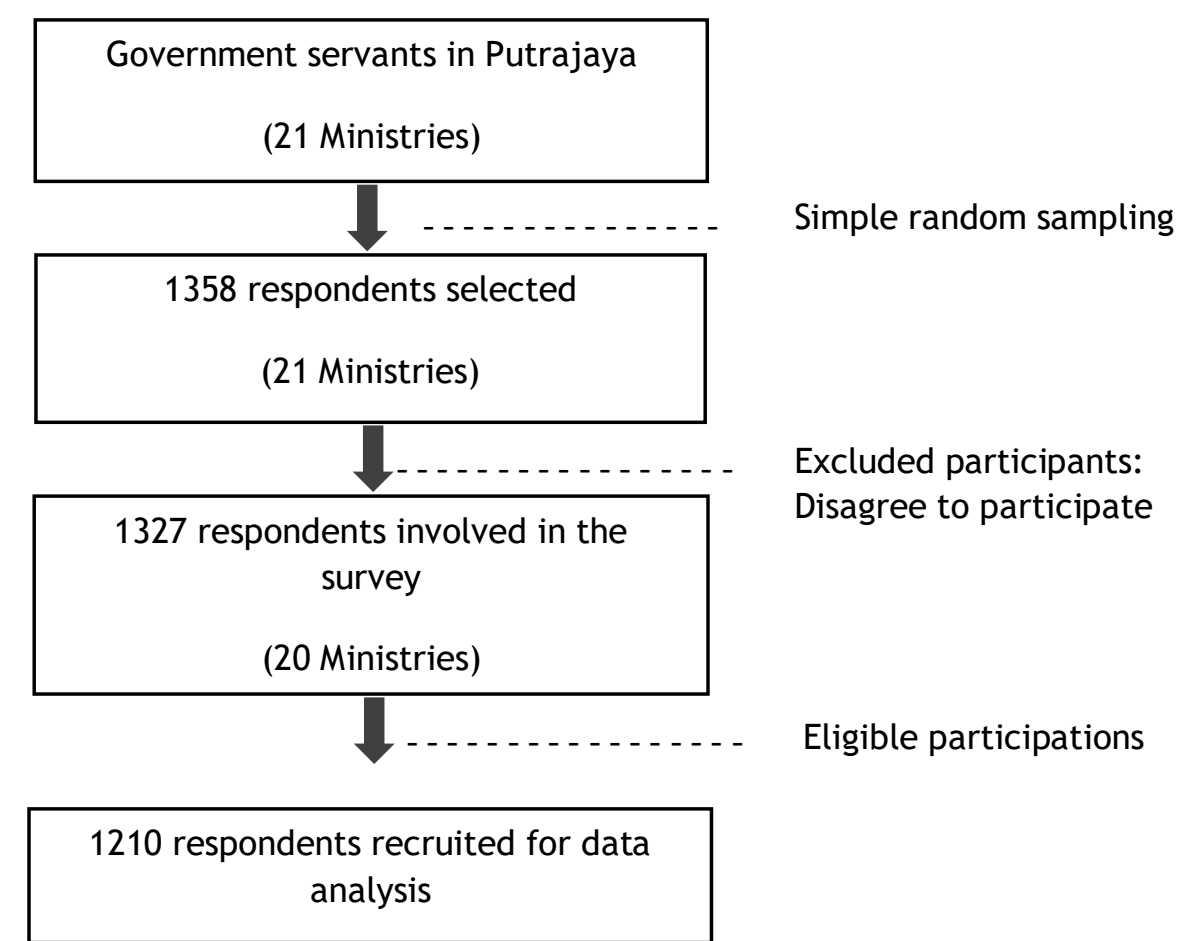

Figure 1 Study flowchart of sample recruitment

\section{RESULTS}

\section{Response Rate}

In total 1358 respondents from all ministries in Putrajaya (21 ministries) had received the questionnaire through the link given during the period of data collection. Of these, only 1327 respondents (20 ministries) had agreed to participate in this survey, giving a response rate of $98 \%(n=1327 / 1358)$. Out of 1327 , only 1210 data from respondents were recruited for data analysis as per the required sample size.

\section{Preference Purchasing Method and The Socio- Demographics}

The majority of respondents had chosen the traditional method over online as their preference for purchasing supplements $(68 \%$, $n=822$ ). Although the result showed that the traditional method of purchasing supplements was the preferred method, however, there was still a minority group that chose online. Logistic regression analysis was performed to identify the significant factors that determined the preferred method of purchasing supplement products online. It was found that the odds of having an online purchasing method were significantly influenced by age (18-45 years old), gender (females), and ethnicity (Indian and other ethnics'). Table 1 provides details of the adjusted and unadjusted odds ratios (ORs), with the $95 \% \mathrm{Cls}$ for the regression model. 
Table 1 Association between Socio-Demographic and Preference Method of Purchasing Supplements $(n=1210)$

\begin{tabular}{|c|c|c|c|c|c|c|c|c|c|c|c|}
\hline & \multicolumn{4}{|c|}{ Preference } & \multirow{4}{*}{ Total } & \multirow{4}{*}{$\begin{array}{c}\mathrm{p}- \\
\text { value }\end{array}$} & \multirow{4}{*}{$\begin{array}{l}\text { Unadjusted } \\
\text { (OR) }\end{array}$} & \multirow{4}{*}{$\begin{array}{c}\text { Unadjusted } \\
\text { OR } \\
(95 \% \mathrm{Cl})\end{array}$} & \multirow{4}{*}{$\begin{array}{c}\mathrm{p}- \\
\text { value }\end{array}$} & \multirow{4}{*}{$\begin{array}{l}\text { Adjusted } \\
\text { (OR) }\end{array}$} & \multirow{4}{*}{$\begin{array}{c}\text { Adjusted } \\
\text { OR } \\
(95 \% \mathrm{Cl})\end{array}$} \\
\hline \multirow{3}{*}{ Variables } & \multicolumn{2}{|c|}{ Traditional } & \multicolumn{2}{|c|}{ Online } & & & & & & & \\
\hline & & & $\mathrm{n}$ & $\%$ & & & & & & & \\
\hline & $\mathrm{n}$ & $\%$ & & & & & & & & & \\
\hline \multicolumn{12}{|l|}{ Age } \\
\hline $18-30$ & 556 & 67.6 & 294 & 75.8 & 850 & 0.000 & 2.12 & $1.48-3.02$ & 0.000 & 2.13 & $1.41-3.21$ \\
\hline $31-45$ & 86 & 10.5 & 49 & 12.6 & 135 & 0.001 & 2.28 & $1.41-3.68$ & 0.008 & 2.16 & $1.22-3.82$ \\
\hline \multirow[t]{2}{*}{$>45$} & 180 & 21.9 & 45 & 11.6 & 225 & & $1.00 *$ & & & $1.00^{*}$ & \\
\hline & 822 & 100.0 & 388 & 100.0 & 1210 & & & & & & \\
\hline \multicolumn{12}{|l|}{ Gender } \\
\hline Male & 305 & 37.1 & 113 & 29.1 & 418 & & $1.00^{*}$ & & & $1.00^{*}$ & \\
\hline \multirow[t]{2}{*}{ Female } & 517 & 62.9 & 275 & 70.9 & 792 & 0.007 & 1.44 & $1.11-1.86$ & 0.020 & 1.38 & $1.05-1.80$ \\
\hline & 822 & 100 & 388 & 100 & 1210 & & & & & & \\
\hline \multicolumn{12}{|l|}{ Ethnicity } \\
\hline Malay & 735 & 89.4 & 365 & 94.1 & 1100 & & $1.00^{*}$ & & & $1.00^{*}$ & \\
\hline Chinese & 23 & 2.8 & 12 & 3.1 & 35 & 0.891 & 1.05 & $0.52-2.14$ & 0.614 & 1.21 & $0.58-2.50$ \\
\hline Indian & 28 & 3.4 & 4 & 1.0 & 32 & 0.021 & 0.29 & $0.10-0.83$ & 0.040 & 0.33 & $0.11-0.95$ \\
\hline \multirow[t]{2}{*}{ Others } & 36 & 4.4 & 7 & 1.8 & 43 & 0.025 & 0.39 & $0.17-0.88$ & 0.023 & 0.38 & $0.17-0.88$ \\
\hline & 822 & 100 & 388 & 100 & 1210 & & & & & & \\
\hline \multicolumn{12}{|l|}{ Education } \\
\hline Secondary Education & 82 & 10.0 & 42 & 10.8 & 124 & & $1.00^{*}$ & & & $1.00^{*}$ & \\
\hline Pre-university & 194 & 23.6 & 121 & 31.2 & 315 & 0.376 & 1.22 & $0.79-1.88$ & 0.518 & 1.16 & $0.74-1.84$ \\
\hline Undergraduate & 325 & 39.5 & 149 & 38.4 & 474 & 0.605 & 0.90 & $0.59-1.36$ & 0.603 & 0.86 & $0.50-1.50$ \\
\hline \multirow[t]{2}{*}{ Postgraduate } & 221 & 26.9 & 76 & 19.6 & 297 & 0.086 & 0.67 & $0.43-1.06$ & 0.265 & 0.69 & $0.36-1.32$ \\
\hline & 822 & 100 & 388 & 100 & 1210 & & & & & & \\
\hline \multicolumn{12}{|l|}{ Grade of position } \\
\hline $11-29$ & 262 & 31.9 & 155 & 39.9 & 417 & & $1.00^{*}$ & & & $1.00^{*}$ & \\
\hline $30-40$ & 90 & 10.9 & 46 & 11.9 & 136 & 0.481 & 0.86 & $0.58-1.30$ & 0.498 & 0.87 & $0.59-1.29$ \\
\hline $41-56$ & 454 & 55.2 & 183 & 47.2 & 637 & 0.004 & 0.68 & $0.52-0.89$ & 0.602 & 1.16 & $0.67-2.01$ \\
\hline \multirow[t]{2}{*}{ Special Grade } & 16 & 1.9 & 4 & 1.0 & 20 & 0.129 & 0.42 & $0.14-1.29$ & 0.206 & 2.87 & $0.56-14.7$ \\
\hline & 822 & 100 & 388 & 100 & 1210 & & & & & & \\
\hline \multicolumn{12}{|l|}{ Salary } \\
\hline RM 1200 - RM 5600 & 471 & 57.3 & 263 & 67.8 & 734 & & $1.00^{*}$ & & & $1.00^{*}$ & \\
\hline RM 5600 - RM 8900 & 238 & 29.0 & 86 & 22.2 & 324 & 0.003 & 0.65 & $0.49-0.86$ & 0.779 & 1.07 & $0.69-1.65$ \\
\hline RM 8900 - RM 14000 & 99 & 12.0 & 34 & 8.8 & 133 & 0.023 & 0.62 & $0.41-0.93$ & 0.988 & 0.99 & $0.62-1.61$ \\
\hline \multirow[t]{2}{*}{ Above RM 14000} & 14 & 1.7 & 5 & 1.3 & 19 & 0.396 & 0.64 & $0.23-1.80$ & 0.634 & 0.66 & $0.12-3.72$ \\
\hline & 822 & 100 & 388 & 100 & 1210 & & & & & & \\
\hline Constant & & & & & & & & & 0.000 & 0.24 & \\
\hline
\end{tabular}

Preference Purchasing Method with The Main Influencing and Motiational Factor

Refers to table 2, the majority answer $(n=568)$ for the most significant reason for choosing the method of purchasing supplements in both the traditional and online group was the product quality with $47.1 \%$ and $46.6 \%$ respectively. Whereas, only $2 \%$ from both groups were significantly influenced by 'the other reasons'.

The respondents were asked a different set of questions based on the nature of their chosen purchasing method. In the traditional group, the majority of respondents had been motivated by the main factor of 'to easily get the product advise and relevant information' ( $n=595,72.4 \%$ ). While in the online group, the majority of respondents had been motivated by the main factor of 'being able to read the product reviews' ( $n=205,52.8 \%$ ) (Figure 2 ).

\section{Preference Purchasing Method and Pre- Purchasing Attitude}

The majority said that the main attitude before they purchase the supplement products was 'to check for many similar products before they decide to purchase it' $(50.9 \%$ traditional and $38.4 \%$ online). Less than five percent of the respondents from both groups $(4.1 \%$ traditional and $0.7 \%$ online) said that they would 'purchase the supplement products which has been recommended by the seller' (Figure 3 ).

\section{Preference Purchasing Method and Knowledge on Identifying Registered Product}

As indicates in table 3 , there was no significant difference between the two groups $(P=0.330)$, when they were asked on how to identify the registered product in the market. Thus, all the knowledge factors would not significantly influence the method preference $(P>0.05)$.

\section{DISCUSSION}

While it was time-consuming, the majority of government servants in Putrajaya preferred to purchase supplement products through the traditional method. It is consistent with what 
was found in studies by Lalwani $D(2017)^{11}$ and Wong (2018) . Interestingly, it appears to contradicts the findings from other studies by Gupta and Sethi (2015) $)^{7}$ and Global Online Consumer Report $(2017)^{1}$, in which online purchasing has been preferred among their respondents. However, all these studies did not specifically focus on purchasing supplements. This preference is most probably due to the type of product ${ }^{11}$, such as health products, must be purchased carefully through the right channel as online purchasing potentially involves a lot of risks ${ }^{7}$.

This study findings also revealed that only age, gender, and ethnicity will influence the preference towards purchase supplements online. Age was reported to influence purchasing behavior with the consideration that younger individuals were more technologically savvy and have more familiarity with the internet than the older cohorts ${ }^{2,7-11}$. In the gender factor, while the survey was voluntary, the female gender was found to be dominant as like what was found in the previous study ${ }^{7}$. However, this finding was contradicted by other studies that discovered the male consumers were more likely to buy items online ${ }^{1}$ and a study also found that women were more skeptical about online purchasing than men, therefore more self-conscious about the website ${ }^{17}$. Interestingly, although there was a study that found that online purchasing was substantially related to the ethnic Chinese groups ${ }^{10}$, this present study found otherwise.

Regardless of the purchasing method, the majority of respondents chose 'product quality' as their very important trait when they purchase any supplement products. This result was the same as what was found in the study by Lalwani $(2017)^{11}$. It is expected when those who preferred the traditional method claimed product quality as their main influencing factor because they can physically evaluate the product and make decisions confidently. However, it is quite surprising when those who chose online also felt that they could evaluate the quality level of a product and this finding was found to contradict the finding by $\mathrm{G}$. Rezai $(2013)^{8}$ study. In this scenario, as mentioned in studies by Gupta and Sethi (2015) and Adjaino (2019) ${ }^{18}$ this factor may be attributed to the online availability of product details, allowing customers to reassure themselves about the seller and make an informed decision. Transparency of a product's information is responsible for prudent purchasing that contributes to prompt decisions.

While there are various motivating factors, their choice for method turned out to be more in technical value which is specifically on the product information in traditional group and, to the social value which is specifically due to being able to read the product reviews in the online group. Those who chose the traditional method were motivated by the opportunity to further ask directly about the product information ${ }^{19}$ in which enhancing their purchasing decision ${ }^{20}$. Meanwhile, those who chose the online method were motivated by being able to read feedback and recommendations made by other consumers, and communicate with them to collect additional knowledge before product purchase ${ }^{11}$. This finding is consistent with the studies done by Sarkar and Das (2017) $)^{21}$ and Wong (2018) $)^{9}$ but disputed with the study done by Lalwani $(2017)^{11}$, which was more towards service (offline channel) and economic (online channel) values.

Respondents' attitudes toward pre-purchasing supplements also influenced the preferred purchasing method. In both groups, they tend to 'check for many similar products before they decide to purchase it' and, a very small number of them bought products that were suggested by the seller. Hence, these results correspond with the research by Lalwani (2017) ${ }^{11}$. One possible explanation for this result is that nowadays, people were finding ways to capitalize on the dissemination of information through technology more than ever, whether in the traditional method or online ${ }^{22}$, and these were further strengthened as Malaysian commonly reviewed the product online prior to purchase ${ }^{23}$.

Surprisingly, no significant difference in knowledge for identifying registered products between traditional and online groups. This can be explained by the fact that people now are more educated than ever before. They actively looked for various information as they lived their lives through multiple purchasing channels ${ }^{22}$. Existing research disclosed that the factor might be due to many buyers using a hybrid shopping strategy where, they visited a physical store to purchase the product, but did an online search for better pricing. In order to complete a purchase service during their shopping, they often integrate online and traditional methods ${ }^{11}$.

Despite attempts to confirm that the findings of this research were both trustworthy and effective, several limitations lied. When considering the results of the current study, the following limitations should be noted. First, the findings of the study cannot be generalized to the entire community in Malaysia as it was conducted in a very small area within the country and focused on the government servants. Second, the findings might be interpreted subjectively since the online survey was subject to participant's recalled bias and untruthful reporting. In addition, a pure causality cannot be found from this cross-sectional study. Nevertheless, this study is able to clarify the current preferred supplements purchasing method and factors associated with it, as there was no known study done yet specifically on the 
supplement products. Thus, it can be used as a pilot study for future studies at the national level. Besides, this study also gives some insight into aspects of influence and significance constraints, particularly on supplement products which may suggest further actions in order to improvise supplements market surveillance by all relevant authorities.

Table 2 Association between the Influence Factor and the Preference Method of Purchasing Supplements $(n=1210)$

\begin{tabular}{ccccccc}
\hline & \multicolumn{9}{c}{ Preference } \\
Influencing Factors & \multicolumn{2}{c}{ Traditional } & Online & Total & p-value \\
& $\mathrm{n}$ & $\%$ & $\mathrm{n}$ & $\%$ & & \\
\hline Product price & 50 & 6.1 & 70 & 18.0 & 120 & \\
Product quality & 387 & 47.1 & 181 & 46.6 & 568 & \\
Purchase at own convenience & 175 & 21.3 & 95 & 24.5 & 270 & $<0.001^{\text {a }}$ \\
Time to acquire the product & 72 & 8.8 & 14 & 3.6 & 86 & \\
Trusting the seller & 121 & 14.7 & 20 & 5.2 & 141 & \\
Other / Lain-lain & 17 & 2.1 & 8 & 2.1 & 25 & \\
& 822 & 100 & 388 & 100 & 1210 & \\
\hline
\end{tabular}

${ }^{\mathrm{a} C h i-s q u a r e ~ t e s t ~}$

Able to read reviews

Easy to find \& compare product

$\cong \quad$ Availability of the product clear Delivery option clear

Easy to follow instruction

Recommended by family \& friends

No need delivery process

Get product advise \& relevant info

Get loyalty \& special offers

Exchange \& return the product
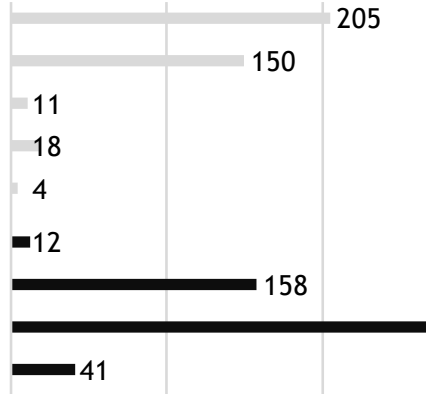

$-16$

Figure 2 Respondence's motivation factors for the preference method of purchasing supplements $(n=1210)$

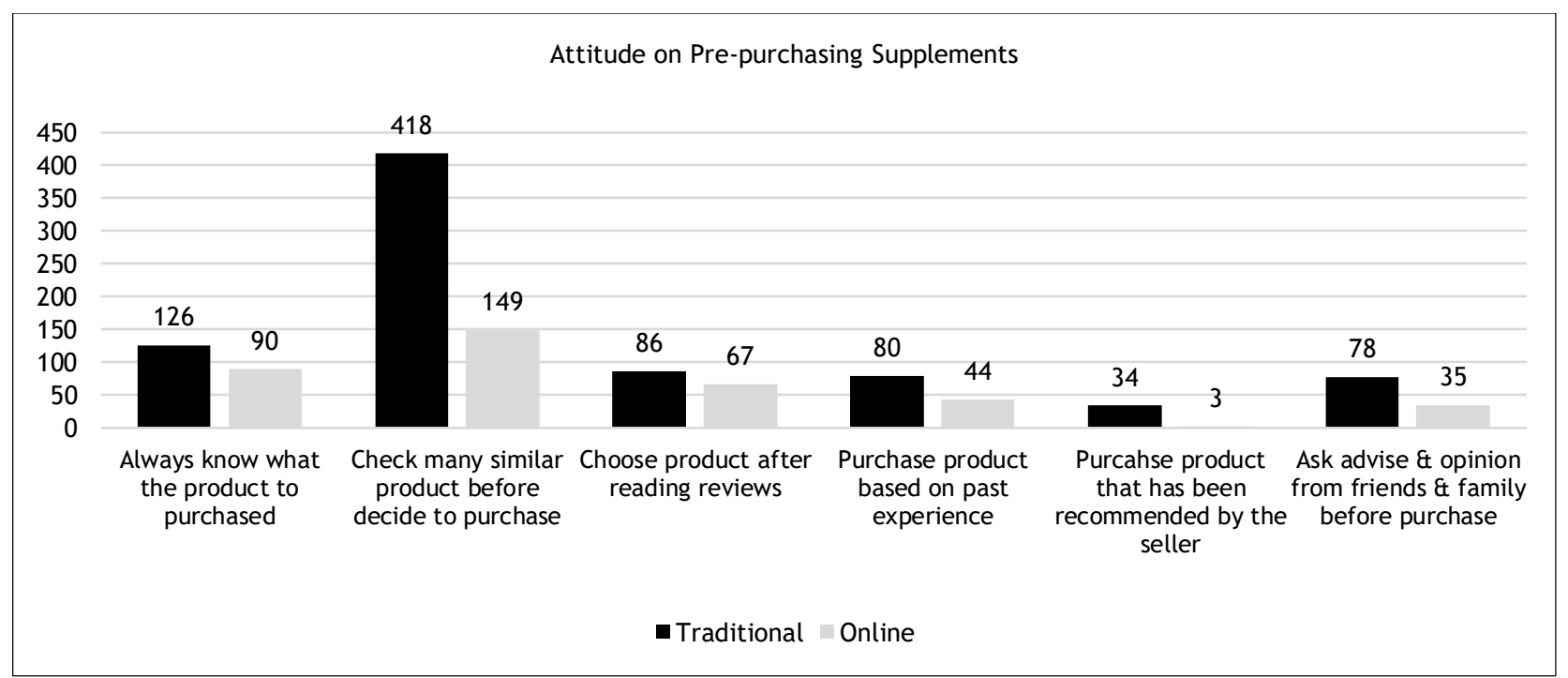

Figure 3 Respondence's attitudes based on the preference method of purchasing supplements $(n=1210)$ 
Table 3 Difference between knowledge factor and preference $(n=1210)$

\begin{tabular}{|c|c|c|c|c|c|}
\hline \multirow{3}{*}{ Variable } & \multicolumn{4}{|c|}{ Preference } & \multirow{3}{*}{$\mathrm{p}$-value } \\
\hline & \multicolumn{2}{|c|}{ Traditional } & \multicolumn{2}{|c|}{ Online } & \\
\hline & mean & SD & mean & SD & \\
\hline Knowledge factors & 5.8 & 1.43 & 5.9 & 1.39 & $0.330^{\mathrm{b}}$ \\
\hline
\end{tabular}

\section{CONCLUSION}

The government servants in Putrajaya preferred to purchase supplement products through the traditional method and the product quality is the major influencing factor in their purchasing decision. Therefore, this study indicates that the awareness of purchasing health products through the look at the items physically would be more appropriate. The data provide insight into various factors that influenced preference of supplements purchasing method and, offers a combination of various focuses to suit the needs of global sustainable development goal (SDG 3), in ensuring healthy lives and promoting wellbeing for all ages. Hence, efforts to increase public knowledge, awareness, and promoting the safety and efficacious issues as well as reemphasize legal action on unregistered supplement products must continue to be implemented by relevant authorities.

\section{Conflict of interest}

The authors declare no potential conflict of interest.

\section{Acknowledgements}

The authors would like to acknowledge all respondents in this project who had taken time out from their busy schedules to participate in this research. The corresponding author would also like to thank Prof Dr. Hazreen Abd Majid who supervised this project and, the University of Malaya for providing guidance and support needed to complete this project.

\section{Funding}

This research received publication funding (RMF0002-2020).

\section{REFERENCES}

1. International $\mathrm{K}$. The Truth about Onl i Ne Consumers 2017 Global Online Consumer Report.; 2017.

2. Fittler et al. Consumers turning to the internet pharmacy market: Crosssectional study on the frequency and attitudes of hungarian patients purchasing medications online. J Med Internet Res. 2018;20(8). doi:10.2196/11115

3. Alan M. Many supplements contain unapproved, dangerous ingredients: study. https://medicalxpress.com/news/201810-supplements-unapproved-dangerousingredients.html. Published 2018. Accessed November 30, 2019.

4. World Health Organization. Orientation Programme on Adolescent Health for Health-Care Providers.; 2014.

5. Williams and McKnight. The Real Impact of Counterfeit Medications. US Pharm. 2014;39(6)(Generic Drug Review suppl):44-46.

https: / / www.uspharmacist.com/article/ counterfeit-meds. Published 2014. Accessed December 1, 2019.

6. Milton. The counterfeit menace | The Star Online. https://www.thestar.com.my/lifestyle/h ealth/2015/01/04/the-counterfeitmenace. Published 2015. Accessed November 30, 2019.

7. Gupta P, Sethi N. Comparative Study of Online and Offline Shopping: A Case Study of Rourkela in Odisha.; 2015.

8. G. Rezai ZMMNS and MZZ. Effect of Consumer Demographic Factors on Purchasing Herbal Products Online in Malaysia.; 2013.

9. Wong et.al. Exploring online and offline shopping motivational values in Malaysia. Asia Pacific J Mark Logist. 2018;30(2):352-379. doi:10.1108/APJML10-2016-0197

10. Harn ACP, Khatibi A, Ismail H bin. ECommerce: A Study on Online Shopping in Malaysia. J Soc Sci. 2006;13(3):231242.

doi:10.1080/09718923.2006.11892554

11. Lalwani D. Young consumers online and offline channel purchase behaviour. 2017.

12. Broekhuizen TLJ. A Conceptual Model of Channel Choice: Measuring Online and Offline Shopping Value Perceptions. Synthesis (Stuttg). 2003;(January):1-37.

13. Ofir C, Simonson I. The effect of stating expectations on customer satisfaction and shopping experience. J Mark Res. 
2007;44(1):164-174.

doi:10.1509/jmkr.44.1.164

14. Marcketti SB, Shelley MC. Consumer concern, knowledge and attitude towards counterfeit apparel products. 2009;33(October 2004):327-337. doi:10.1111/j.1470-6431.2009.00748.x

15. Wahida Zulkifli N, Amir Mohd Yunus M, Fakarul Radzi Mohamed Mustafa M, et al. A Survey on Knowledge of Registered Drugs amongst Patients from the Specialist Clinic, Malaysia. Al-Nahrain J Sci. 2019;22(3):26-34. doi:10.22401/anjs.22.3.04

16. Zulkifli NW, Aziz NA, Hassan Y, Hassali MA, Bahrin NLZ. Development of Validated Questionnaire to Access Public Knowledge on Registered Drugs. Procedia - Soc Behav Sci. 2015;172:749-753. doi:10.1016/j.sbspro.2015.01.428

17. Slyke C V., C. L. Comunale A, Belanger. F. "Gender Differences in Perceptions of Web-Based Shopping,." New York. 2002;45(57):1-5.

18. Adjaino V. Shoppers' Experience With Traditional and Online Shopping in Benin City. 2019;1(July):169-181.

19. Malek S, Taylor J, Mansell K. A questionnaire examining attitudes of collegiate athletes toward doping and pharmacists as information providers. Can Pharm J. 2014;147(6):352-358. doi: $10.1177 / 1715163514552559$

20. Weiss M, Grey E, Family $H$, Tsuyuki R, Sutton J. The role of the multidisciplinary team and its effect on the clinical roles of community pharmacists. 2014;(May):1-72.

21. Sarkar R, Das DS. Online Shopping vs Offline Shopping: A Comparative Study. 2017. 2017;3(1):1367-1368.

22. Bachrach D, Ogilvie J, Rapp A, Calamusa J. More Than a Showroom: Strategies for Winning Back Online Shoppers. 1st ed. Palgrave McMillian, US.; 2016.

23. Nielsen. MALAYSIANS RANK AMONG THE WORLD'S MOST AVID ONLINE SHOPPERS. Nielsen.

https://www.nielsen.com/my/en/pressreleases/2014/e-commerce/. Published 2014. Accessed November 1, 2020. 